\title{
Perspectivas e Desafios da Gestão Pública Contemporânea
}

\author{
Istefani De Sá Nunes ${ }^{1}$; Hesler Piedade Caffé Filho ${ }^{2}$
}

\begin{abstract}
Resumo: Quando nos referimos a Gestão Pública, estamos nos referindo à administração, organização e controle de atos ou ações destinadas à organização da vida social, à garantia de direitos, à melhoria das condições de vida da população. Desta forma, a política pública aparece como uma ferramenta de gestão. Executar políticas públicas é lutar pela efetivação dos direitos sociais na vida da população. Pode-se interpretar os direitos sociais como principais serviços ofertados pelo Estado no sentido de proporcionar um 'bem-estar' da sociedade. O artigo visa fazer uma introdução ao estudo de Gestão das Políticas Públicas, destacando as tendências e paradigmas da gestão pública contemporânea, enfatizando as suas especificidades e analisando, particularmente, alguns temas da agenda da gestão pública democrática tais como: a ideia de governança, eficiência, governo eletrônico, transparência, accountability, parcerias com o setor privado, especialmente o $3^{\circ}$ setor, participação e descentralização. Ao longo deste trabalho, foram apresentados os principais conceitos e aspectos relacionados ao tema da Gestão Pública. Destacou-se sua importância para o bom atendimento das necessidades sociais. Todos os conceitos abordados neste capítulo são essenciais para o estudo da Gestão Pública. Não obstante, cuidar da administração dos serviços públicos, buscar a qualidade e a satisfação plena das necessidades sociais é tarefa de cada um dos administrados. Os tópicos acima apontam para a construção e criação de possibilidades cotidianas de participação. Somente a partir da instituição de uma nova cultura de participação poderemos alcançar uma nova consciência democrática, valorizando o capital humano na conquista da cidadania. No próximo tópico, definiremos o conceito de capital humano e exploraremos com mais propriedade o campo da gestão pública.
\end{abstract}

Palavras-chave: Gestão Pública; Eficiência; Inovação; Municípios.

\section{Prospects and Challenges of Contemporary Public Management}

Abstract: When we refer to Public Management, we are referring to the administration, organization and control of acts or actions aimed at the organization of social life, guaranteeing rights, and improving the living conditions of the population. In this way, public policy appears as a management tool. To execute public policies is to fight for the realization of social rights in the life of the population. Social rights can be interpreted as the main services offered by the State in order to provide a 'welfare' of society. The article aims to make an introduction to the study of Public Policy Management, highlighting trends and paradigms of contemporary public management, emphasizing their specificities and analyzing, in particular, some themes of the democratic public management agenda such as: the idea of governance, efficiency, e-government, transparency, accountability, partnerships with the private sector, especially the third sector, participation and decentralization. Throughout this paper, the main concepts and aspects related to Public Management were presented. Its importance was emphasized for the good attendance of social needs. All the concepts discussed in this chapter are essential for the study of Public Management. Nevertheless, taking care of the administration of public services, seeking the quality and full satisfaction of social needs is the task of each one of them. The topics above point to the construction and creation of everyday possibilities of participation. Only through the institution of a new culture of participation can we achieve a new democratic consciousness, valuing human capital in the conquest of citizenship. In the next topic, we will define the concept of human capital and explore more fully the field of public management.

Keywords: Public Management; Efficiency; Innovation; Counties.

\footnotetext{
${ }^{1}$ Graduada em Direito pela Faculdade de Ciências Humanas e Exatas do Sertão do São Francisco- FACESF (2017); Estudante de Pós Graduação em Gestão Pública Municipal pela UNIVASF (2019). Contato: fanny_gt@ hotmail.com;

${ }^{2}$ Administrador pela Universidade Estácio de Sá (2005); MBA em Gestão Estratégia de Negócios- Escola Eng. Eletromecânica da Bahia (2006); Especialista em Marketing pela Faculdade São Francisco de Juazeiro (2007); Mestre em Gestão de Políticas Públicas pela Univ. Federal Recôncavo Baiano (2015). Atuando como Professor de Graduação e Pós dos cursos de Gestão Pública da Univasf (2014); Coordenador da Especialização em Gestão Pública da Univasf (2019); Coordenador MBA em Logística da FASJ (2019). Contato: hesler.caffe@ univasf.edu.br.
} 


\section{Introdução}

O atual cenário da gestão pública está marcado pela reiteração constante de atitudes e ilegalidades sofridas por parte dos gestores. Os casos de envolvimento de escândalos e corrupção nas esferas do poder público têm tomado conta dos noticiários e preocupado bastante a população, uma vez que essas ações reiteradas têm afundado a economia do País.

De acordo com Matias-Pereira (2010), os desafios da gestão contemporânea são frutos das mudanças ocorridas na sociedade. Mudanças estas que ocorrem principalmente devido ao crescente processo de globalização. Além disso, o autor destaca que além da preocupação em elevar o nível de desempenho da gestão pública, o governo deve dedicar atenção especial às questões que envolvam moral, a ética e a transparência da administração pública, além de fortalecer a capacidade de formulação e implementação de novas políticas públicas.

Com o tempo, as pessoas envolvidas no controle social tendem a uma melhor compreensão de como funcionam as políticas, e passam a ter uma atuação interventiva com mais qualidade, apropriando-se dos termos utilizados, regras que se devem cumprir, conhecer como funciona a burocracia, os prazos adotados pelo poder público dentre outras.

O importante é consolidar um processo de aprendizado e formação de maneira contínua e permanente. Que deve ser alimentado nos espaços autônomos de organização da sociedade.

Pretende-se com o presente trabalho contextualizar a origem da expressão 'Gestão Pública', abordando conceitos fundamentais, como Controle Social, Participação e Descentralização, bem como refletir acerca dos principais desafios e estratégias postos à gestão pública brasileira.

Segundo o dicionário essencial da língua portuguesa, Gestão significa: “1. Ação ou efeito de gerir; gerência; 2. Período durante o qual a diretoria de uma empresa ou instituição exerce os atos administrativos; 3. Tentativas." Quando falamos sobre Gestão Pública, estamos falando sobre a participação da sociedade civil organizada (associação de moradores, clubes de mães, movimentos sindicais, movimentos sociais, grupos de igrejas, pastorais) na tomada de decisões junto ao poder público. Essa participação só foi possível a partir da luta pela redemocratização da sociedade brasileira ocorrida nos anos de 1980.

716 Id on Line Rev. Mult. Psic. V.13, N. 45, p. 715-733, 2019 - ISSN 1981-1179 Edição eletrônica em http://idonline.emnuvens-.com.br/id 
O conceito de política pública será abordado, por entendermos que este conceito assume lugar central na discussão sobre gestão pública.

\section{A Política Pública como ferramenta de Gestão}

Acreditamos na superação gradual de um antigo desconhecimento que leva pessoas a afirmarem que não gostam de política, que sentem aversão à mesma. A política faz parte das nossas vidas cotidianamente. Independente de sexo, religião ou classe social, todos somos sujeitos sociais e como tal, seres políticos.

Vimos que Política é a arte de governar. Neste sentido, um primeiro conceito de política pública que nos aparece está relacionado à oferta de serviços essenciais à população, ao público enquanto sociedade. A escola pública do bairro, o posto de saúde, a quadra esportiva, os serviços de segurança pública (presídios, delegacias), os programas sociais (Bolsa família, Projovem), enfim, todos os serviços sociais oferecidos pelo Estado estão ligados a uma política pública.

Observe, que é dever do Estado prover, assegurar, garantir condições básicas de vida à população. Não se trata de uma opção e sim de uma obrigação legal imposta à administração pública, oferecer serviços de qualidade à população como garantia dos direitos sociais. $\mathrm{O}$ art. $6^{\circ}$ da Constituição Federal de 1988 elenca os direitos sociais:

“Art. $6^{\circ}$ São direitos sociais a educação, a saúde, a alimentação, o trabalho, a moradia, o lazer, a segurança, a previdência social, a proteção à maternidade e à infância, a assistência aos desamparados, na forma desta Constituição." (CONSTITUIÇÃO FEDERAL, 1988)

Durante muito tempo, sobretudo nos séculos XVIII e XIX, a principal função do Estado era garantir a segurança pública diante de ameaças de guerras. Com o aprofundamento da democracia, as responsabilidades do Estado se ampliaram para outros setores: saúde, educação, meio ambiente, habitação, etc.

A visão apresentada pelo autor acima referido nos apresenta um conceito de política pública enquanto um conjunto de princípios, regras e ações a serem executadas pelo poder 
público, com recursos públicos, para a satisfação de necessidades sociais. Estas regras e princípios aparecem sistematizadas, geralmente na forma de leis, programas e projetos. Logo, existe um momento de planejamento e elaboração de cada política pública a ser executada, conforme veremos no terceiro capítulo deste trabalho.

Outro aspecto que nos chama a atenção no trecho acima citado é a dependência da política pública ao exercício do fazer/poder político. De acordo com o autor, as omissões dos que ocupam cargos políticos (governo) também devem ser consideradas como manifestações políticas por representarem as opções e orientações dos governantes. Em outras palavras, o sucesso de uma política pública depende também de vontade política. Nas palavras de Teixeira (2002, s.p.):

\begin{abstract}
A participação cada vez maior da sociedade civil organizada nas tomadas de decisões públicas tem garantido a inclusão de demandas sociais antes excluídas da agenda oficial. Fazendo um recorte para a área da infância e adolescência, durante a década de 1980, os movimentos sociais lutaram nas ruas brasileiras contra os maus tratos impingidos a crianças e adolescentes.
\end{abstract}

Com o peso de um milhão e meio de assinaturas, o artigo 227 da Constituição Federal de 1988 assim dispõe:

"É dever da família, da sociedade e do Estado assegurar à criança e ao adolescente, com absoluta prioridade, o direito à vida, à saúde, à alimentação, à educação, ao lazer, à profissionalização, à cultura, à dignidade, ao respeito, à liberdade e à convivência familiar e comunitária, além de colocá-los a salvo de toda forma de negligência, discriminação, exploração, violência, crueldade e opressão." (CONSTIUIÇÃO FEDERAL, 1988)

O processo de manifestação contra as formas de violência e maus tratos contra a mulher também pode ser entendido como um movimento instituinte, de mudança de paradigmas. Com a aprovação da Lei $\mathrm{n}^{\circ}$ 11.340, de 07 de agosto de 2006, nomeada Lei Maria da Penha, os direitos da mulher foram estabelecidos em primeiro plano, gerando um reordenamento de ações e conceitos relacionados à questão de gênero.

Nos dois exemplos citados (criança/adolescente e mulher), observamos que a partir das manifestações de massa, por meio dos movimentos sociais os direitos foram assegurados em lei. Outros segmentos também conquistaram direitos no plano legal, como o idoso, o negro, o homossexual. A partir dessas conquistas (elaboração de leis específicas para segmentos 
populacionais específicos), são elaborados programas, planos, projetos e ações no sentido de efetivar, executar as leis. Este arcabouço sistematizado de ações são políticas públicas.

Relembrando as lições dos cientistas políticos, a principal diferença entre Governo e Estado é que o Governo é transitório; o Estado é fixo. Portanto, as 'Políticas Governamentais' fazem parte de um governo específico e representam os ideais de um grupo, num determinado momento/contexto, independente da vontade popular. Por outro lado, a Política Pública deve ser pública desde a sua gestação até a colheita dos seus resultados. Deve, pois, ser pensada junto aos interessados pelos benefícios que ela trará. Em outras palavras, a política pública deve ser feita com e não para o cidadão.

Outro aspecto relevante sobre as políticas públicas é que elas visam atender a demandas sociais advindas, principalmente, de segmentos e setores historicamente excluídos. Para existirem, dependem do grau de organização, mobilização e negociação dos que a solicitam. Seus objetivos principais são ampliar e efetivar direitos sociais, também criados a partir das lutas e dos conflitos sociais e que passam a ser reconhecidos na forma da lei (Lei Maria da Penha, ECA, Estatuto do Idoso). Segundo Teixeira (2002):

Devemos chamar a atenção para um aspecto importantíssimo relacionado às políticas públicas: o papel do Estado. A política pública não pode ser concebida e administrada privadamente, mas deve o Estado fazer o que é função dele. Antes, precisamos relembrar da discussão sobre o neoliberalismo, que pode ser traduzido em ideias políticas e econômicas, capitalistas, que defendem a não participação do Estado na economia, devendo haver liberdade total de comércio, sem regulamentações, imperando o livre mercado, o que beneficia apenas às grandes potências e empresas multinacionais. Algumas consequências do neoliberalismo podem ser apontadas na experiência brasileira, sobretudo aquelas vividas nos governos de Fernando Collor de Melo e Fernando Henrique Cardoso: aumento do desemprego, diminuição de salários, cortes de verbas para o setor social, privatizações, aprofundamento da dívida externa e dependência de capital internacional.

Em linhas gerais, o Estado existe para garantir a ordem e, na medida do possível, garantir o bem comum da sociedade. Com a onda das privatizações, tem acontecido o inverso: um constante enxugamento do Estado e a transferência de suas responsabilidades para o terceiro setor, sobretudo para as ONG's. Por isso a necessidade da participação no controle do exercício 
e das funções estatais, que devem se nortear por políticas originadas da sociedade civil, criadas com as experiências práticas de cidadania.

Portanto, a formulação de políticas públicas e sua execução dependem, para um resultado satisfatório, de que as necessidades sociais sejam colocadas frente ao Estado, não o considerando um Estado tutelar, doador, assistencialista, compensatório, mas controlando o Estado, tentando incluir na agenda estatal o que convém aos cidadãos. Esta relação de negociação de demandas e interesses entre o poder público e a sociedade civil organizada reflete ideias relacionadas ao controle social, que veremos com mais clareza no capítulo seguinte.

\section{A Descentralização, a Participação e o Controle Social}

Após conceituarmos o termo políticas públicas, passemos à análise do processo de descentralização política e administrativa dos serviços públicos, ocorrida no Brasil, por volta dos anos de 1980, associada ao processo de redemocratização. Este processo de descentralização contribuiu para que a gestão das políticas públicas acontecesse nos três níveis da federação: federal, estadual e municipal.

O fenômeno da descentralização está associado a problemas de governabilidade. Tratase da transferência de poder político-econômico para unidades subnacionais de governo (Estados e Municípios). Com a descentralização, aumentaria a eficiência do setor público como prestador de serviços à população. De acordo com Affonso (2000):

\footnotetext{
"Na América Latina a descentralização tem estado associada aos processos de redemocratização a partir dos anos 80 , à crise fiscal dos governos centralizados e a problemas de governabilidade. De uma forma geral, a descentralização fiscal iniciouse com a decisão de se transferir para os governos subnacionais algumas das atribuições do governo central para, em um segundo momento, negociarem-se as assignações de recursos compatíveis com as novas atribuições. Em alguns casos, a cronologia foi inversa: primeiro ocorreu a descentralização de recursos e, em seguida, a transferência de atribuições." (AFFONSO, 2000, p. 128).
}

Quanto maior o poder, maior as responsabilidades. Junto com a transferência de poder (recursos financeiros, autonomia de gestão, espaços de decisões), foram transferidas 
responsabilidades (competências, cargos, funções) aos governos subnacionais. O grande objetivo da descentralização é melhorar a gestão pública, com vistas à otimização dos recursos públicos, eficiência das ações e, sobretudo, aproximar os serviços públicos da realidade, possibilitando que as ações sejam planejadas a partir do nível da federação na qual elas serão implantadas.

Para um melhor entendimento sobre o processo de descentralização, lancemos mão sobre os conhecimentos jurídicos. No campo do direito administrativo, encontramos que a função primordial do Estado é oferecer utilidades aos administrados, justificando sua existência e atuação no fato de servir ao interesse público. Logo, sempre que o Estado agir, deve ser em favor da coletividade.

Sanches (1999), afirma que os serviços públicos nem sempre dependeram da vontade ou necessidade do cidadão. De acordo com o autor:

\begin{abstract}
Após estabelecido o conceito de serviço público, precisamos entender que eles acontecem nas três esferas governamentais: federal, estadual e municipal. Por exemplo, os serviços de assistência social estão alocados conforme a esfera governamental: no nível federal, temos o Ministério de Desenvolvimento Social e Combate à Fome - MDS; no nível Estadual (Maranhão), temos a Secretaria Estadual de Desenvolvimento Social - SEDES; no plano municipal (São Luis - MA), temos a Secretaria Municipal da Criança e Assistência Social - SEMCAS. Em cada nível estão estabelecidas as funções, atribuições, cargos e demais competências para a execução da Política Nacional de Assistência Social.
\end{abstract}

Quando o próprio Estado (governo federal, estadual ou municipal) executa os serviços públicos, a doutrina jurídica classifica essa prestação de serviço como Execução Direta. Por exemplo, a execução do Projovem ou do Programa Bolsa Família são feitas diretamente por Secretarias e órgãos ligados ao poder executivo. Os dois serviços públicos exemplificados estão ligados diretamente ao MDS. Nestes casos, o Estado centraliza as atividades. "O Estado, na função de administrar assumirá diretamente seus encargos." (SANTOS, apud SANCHES, 1999 s.p.)

A Execução Indireta ocorre quando os serviços públicos são prestados por terceiros, sob a fiscalização e controle do Estado. Fazem parte da administração indireta, por exemplo, o Banco Central, o Instituto Nacional de Seguridade Social - INSS, a Caixa Econômica Federal, a Empresa de Correio e Telégrafos (correios), o Instituto Brasileiro de Geografias e Estatísticas 
- IBGE. Essa execução, quando prestada por terceiros, sob a fiscalização e controle do titular (Estado), se chama descentralização.

Após realizarmos este preâmbulo, podemos agora nos deter nos marcos conceituais do processo de descentralização. Lobo (1990) afirma que a descentralização pode representar um instrumento de democratização do Estado e de maior alcance da justiça social, se constituindo numa alternativa para a reordenação dos serviços públicos. De acordo com Lobo:

\begin{abstract}
"Embora sejam reconhecidas por todos as dificuldades de ordem econômicofinanceiras enfrentada pelo país, admite-se, quase consensualmente, que a forma de estruturação interna do Estado, seus atuais arranjos político-institucionais, não contribuem para um desempenho eficaz das ações governamentais. Recorre-se, então, à causa básica do que se pode chamar de "desordem" do Estado - a centralização de poderes e recursos em mãos da União - para encontrar a alternativa de solução para o impasse: a descentralização.” (LOBO, 1999, p. 6)
\end{abstract}

Observe que, conforme já foi dito, a descentralização surge a partir da década de 1980, concomitante ao final do período de ditadura, quando imperava no Brasil um governo repressor e centralizador. A luta da sociedade era pela democratização, liberdade de expressão, pela participação nas decisões públicas.

Sobre a interpretação do termo descentralização, Lobo (1999) alerta para a confusão que acontece com frequência em relação aos termos descentralização e desconcentração:

"Dentre as várias interpretações, destaca-se como bastante comum a que confunde
descentralização com desconcentração. Não é raro perceber-se, em discursos oficiais,
e mesmo em programas governamentais a utilização dos dois termos como sinônimos.
Mais frequente, ainda, é o uso da palavra "descentralização" quando, na verdade, está
se tratando de ações que mais diretamente dizem respeito a uma pura desconcentração.
Ou seja, mudanças que levam em conta uma dispersão físico-territorial das agências
governamentais que até então estavam localizadas centralmente." (LOBO, 1999, p. 6)

O grande problema desta confusão, é que a desconcentração (distribuição de agencias e instituições governamentais pelo território brasileiro), não ameaça as estruturas consolidadas. $\mathrm{Na}$ descentralização, acontecem profundas alterações nas estruturas de poder. Conforme Lobo (1999):

“(...) a descentralização envolve necessariamente alterações nos núcleos do poder decisório até então centralizado em poucas mãos. Esta a razão por que fica mais cômodo e tranquilo para o governo assentado em bases centralistas privilegiar a desconcentração e rotulá-la de descentralização." (LOBO, 1999, p. 6) 
A referida autora destaca três vertentes de descentralização: da administração direta para a indireta, entre níveis de governo e do Estado para a Sociedade Civil.

A primeira vertente, conforme abordamos no início deste capítulo, se refere à criação de empresas públicas, autarquias e sociedades de economia mista que foram distribuídas ao longo do território nacional. Esta vertente está mais ligada aos conceitos abordados no campo do direito administrativo, conforme vimos anteriormente. Não podemos deixar de citar as críticas coesas que Lobo (1999) tece em relação a este tipo de descentralização:

\footnotetext{
"Se, para algumas situações isto se revelou vantajoso [descentralização da administração direta para a indireta], geralmente àquelas funções ligadas à atividade econômica, para outras serviu apenas, entre outros problemas, pare estimular o clientelismo político e a criação de estruturas paralelas, superpondo recursos e esforços às atividades desenvolvidas pela administração direta. Tal processo teve também, como consequência, uma perda de controle da administração central sobre a indireta, além de estigmatizar a primeira como inoperante, ineficiente, emperradora da máquina". (LOBO, 1999, p. 7)
}

A segunda vertente, onde a descentralização acontece entre os níveis de governo, diz respeito à distribuição de responsabilidades e recursos financeiros aos governos subnacionais. Trata-se da redistribuição de receitas públicas e da institucionalização de novos arranjos no sistema de competências governamentais. As críticas às experiências desse modelo de descentralização apontam para uma indefinição de competências, dispersão de esforços e recursos e a não responsabilização de entes públicos pela não prestação de serviços.

A terceira vertente diz respeito à transferência de funções do setor público (Estado) para serem executadas exclusivamente ou em cooperação com o setor privado. Este tipo de descentralização acabou por criar o terceiro setor, numa tipificação onde o estado é o primeiro setor, o mercado é o segundo setor e as ONG's e entidades filantrópicas se constituem no terceiro setor. Exemplo claro são as ONG's que atuam em diversas linhas e segmentos, desempenhando funções que antes eram exclusivamente do Estado. Vale ressaltar que nesta vertente, também estão incluídos como atores cooperantes as associações de moradores, os sindicatos de trabalhadores, clubes de mães e demais instituições organizadas da sociedade civil. 
Outro aspecto importante a ser discutido se refere à municipalização. $\mathrm{O}$ conceito de municipalização está relacionado à transferência de serviços públicos dos governos federal e estadual para os municípios, o que pode gerar dois sentidos distintos. Conforme Lobo (1999):

\begin{abstract}
"Municipalizar, para alguns, significa uma articulação das forças do município como um todo para a prestação dos serviços, ou seja, prefeitura municipal e organizações da sociedade civil como co-responsáveis pela prestação dos serviços. Para outros, municipalizar pode querer dizer 'prefeiturar', entendendo assim a exclusividade da administração municipal no processo.” (LOBO, 1999, p. 7-8)
\end{abstract}

Não podemos esquecer-nos de mencionar que o município é o lócus (espaço) da prestação e oferta dos serviços públicos mais próximos do cidadão. Em outras palavras, a gestão pública se materializa no município, onde os serviços ganham destinatários. É onde ocorre a consecução dos objetivos institucionais. Neste sentido, municipalizar também pode privilegiar a participação dos cidadãos no fazer público.

Observe, que todo esse percurso teórico representa um caminho necessário para chegarmos ao nosso objetivo principal: Gestão Pública. Conforme assinalamos no início deste trabalho, a referida expressão em destaque só pode ser entendida no contexto da descentralização dos serviços públicos. Somente quando os serviços chegam até o cidadão é que se tem um processo de gestão. Gestão Pública nada mais é do que a administração dos serviços públicos, desde o planejamento até a avaliação, passando pela fiscalização do cidadão.

Aliás, a participação popular e as conquistas sociais no Brasil foram sempre marcadas pela mobilização, fiscalização e luta pelo controle social. A Constituição Federal de 1988 é fruto desse processo de mobilização. Neste sentido, o Controle Social é a participação do cidadão na gestão pública. Trata-se de um mecanismo de enfrentamento e prevenção da corrupção, bem como visa o fortalecimento da nossa democracia.

Nesse processo de fiscalização dos serviços públicos, fica difícil considerar um Estado que seja de todo bom ou de todo condenável. O que não pode se perder de vista é que a sociedade civil precisa controlar o Estado e que o Estado tem a tendência de escapar à sociedade civil.

A origem da expressão controle social está ligada à sociologia. Foi criada para expressar a integração da sociedade civil na fiscalização dos gastos e serviços públicos, buscando qualificar as ações do Estado e atender as demandas da população. Historicamente, o Estado 
sempre foi um braço da burguesia. Por esta razão, para atender às necessidades da maioria da população, é preciso que se tenha mecanismos de controle sobre as ações estatais.

Herbert de Souza, o 'Betinho', contribuiu de forma significativa com a definição do conceito de participação.

Com a clareza de um cristal, concedida pelo ilustre pensador acima citado, podemos entender que a participação está nas relações sociais e mesmo nas relações cotidianas, no nosso dia a dia. A responsabilidade do que acontece em nossa casa, comunidade, cidade, país e até mesmo no planeta, é de cada um de nós. Portanto, a participação está para todos e não apenas para alguns privilegiados. Participar da sessão da câmara legislativa, da reunião da associação de moradores, de algum Conselho de Direito (criança e adolescente, mulher, idoso etc.), de algum movimento social, de algum grupo de trabalho social ligado a uma instituição religiosa, de alguma ONG, são formas de intervir na vida social e definir novos rumos à gestão pública.

A participação pode nos levar a um novo status quo, ou seja, a um novo patamar onde a democracia seja vivida com plenitude, onde a corrupção seja combatida com seriedade e eficácia, onde possamos viver um status de cidadãos, e não apenas um ideal. Para isso, há necessidade de mudanças culturais, mudanças na nossa forma de agir e de pensar.

"Na cultura brasileira, a participação é percebida de forma limitada e limitante: "seja um bom pai de família e o resto virá por acréscimo"; "seja um bom trabalhador que os outros cuidarão de sua vida"; "seja um cidadão que vota a cada quatro ou cinco anos e o Estado fará o resto"; "não participe de tudo nem busque ampliar seus compromissos; isso só lhe trará dor de cabeça!". No fundo, a mensagem conformista e excludente é essa: cuide de sua vida e esqueçase do resto!" (SOUZA, 2004, s.p.)

Historicamente, o autoritarismo nos levou (e ainda tem nos levado) a ter medo de participar, o que tem limitado a vivência de direitos sociais e da cidadania. Mas a própria história nos traz exemplos de força e transformação. Quando o povo quer, o povo consegue. Exemplo desta afirmação é o impeachment do ex presidente Fernando Collor de Melo, que reuniu uma multidão nas ruas, com as 'caras pintadas', lutando pela retirada de um presidente que já não mais satisfazia aos anseios da população.

"Participação é conquista". Com esta frase, Pedro Demo demarca que o campo da participação é o campo da liberdade. Afirma que não nos interessa aquela participação 
concedida, dada, outorgada, mas sim aquela conquistada. Gama (2007), baseado nas ideias de Demo (1996), afirma que:

\begin{abstract}
“É muito mais fácil governar sem participação. Por isso, o cidadão deve conquistar este espaço, esta liberdade de participar. Deve fazer o caminho de volta no sentido de que ele um dia delegou a outra pessoa o seu poder político e nunca mais se preocupou com o que estava sendo feito com a sua parcela de poder delegada com legitimidade. Ele deve rever o seu ato e correr atrás da história. Mas daí, as pessoas que receberam aquela parcela de poder dele já se acostumaram e incorporaram aquela parcela de poder ao seu e se sentem poderosas como se todo aquele poder fosse seu. Poderosa inclusive para reprimir os movimentos de reconquista do direito de participação. Por isso é preciso reconquistar este poder através da participação. (...) $\mathrm{O}$ trabalhador que durante séculos teve o seu trabalho alienado, tem uma dificuldade natural de fazer o caminho de volta." (GAMA, 2007,m s.p.)
\end{abstract}

A participação é, pois, uma valiosa aliada no enfrentamento da questão social. O aspecto da alienação abordado pelo autor acima citado diz respeito à pobreza política instalada e enraizada em nosso país. Em sua obra intitulada Pobreza Política, Pedro Demo demarca com precisão que a pobreza não se resume ao aspecto material, e que não pode ser definida apenas como carência de alguma coisa. Para além disso, a pobreza é determinada por aspectos históricos, culturais e políticos, que marcam a cultura da não participação.

Demo (1996) chama a atenção para o fato de que a democracia deve ser vivida a todo momento em nossas ações cotidianas, nas relações familiares, com amigos, na comunidade e instituições das quais participamos. A democracia deve ser exercida no cotidiano, diariamente, e se tornar comum, ao contrário da 'falsa' democracia que vivemos, que acontece de tempos em tempos, sobretudo no período de eleição.

Cultivar a participação é, pois, assumir a tarefa de decidir sobre o futuro da vida social e estabelecer as condições de autodeterminação. De acordo com Demo (1996):

\footnotetext{
"Participação é o processo histórico de conquista das condições de autodeterminação. Participação não pode ser dada, outorgada, imposta. Também nunca é suficiente, nem prévia. Participação existe, se e enquanto for conquistada. Porque é processo, não produto acabado. Pela mesma razão é igualmente uma questão de educação de gerações. Não se implanta por decreto, nem é consequência automática de qualquer mudança econômica, porque tem densidade própria, embora nunca desvinculada da esfera da sobrevivência material." (DEMO, 1996, p. 97-98)
}

Antes de passarmos ao tópico reservado para o aprofundamento sobre a gestão pública, vejamos alguns canais de participação indicados por Demo (1996). Segundo ele, a qualidade 
dos serviços públicos de uma sociedade passa pela definição e clareza dos canais de participação da população. Desta forma, Demo destaca 05 (cinco) canais de participação (DEMO, 1996, p. 95-96):

1) Organização da sociedade civil - está representada pela organização de lideranças comunitárias, pela legitimidade do processo, pela participação da base e pelo planejamento participativo;

2) Planejamento participativo - são aquelas formas de participação em parceria com o Estado, criadas pela administração pública. Embora devam ser sob suspeita, também podem significar possibilidade de participação popular, desde que apresentem organização e qualidade política;

3) Educação básica - Segundo Demo: “A universalização do $1^{\circ}$ grau é entendida como canal de participação, por que sua finalidade precípua é tipicamente política: aprende-se a ler, escrever e contar para 'saber as coisas', ou seja, para poder ser menos objeto das prepotências e destino.” (DEMO, 1996, p. 94)

4) Identidade cultural comunitária - está relacionada com o sentimento de pertencimento a um grupo, ter uma história, fazer parte de um povo marcado com características singulares e com uma história comum. É se sentir parte de um grupo. 5) Conquista de direitos - por mais que os direitos sejam reconhecidos nas leis, precisamos conquistá-los na realidade. “(...) se o Estado for a delegação autêntica de uma cidadania vigilante e competente, pode comprometer-se com os canais de participação e colaborar na montagem de uma sociedade onde a democracia não seja euforia, mas modo de vida." (DEMO, 1996, p.97)

\section{A Constituição Federal de 1988 e o conceito de Gestão Pública}

Em 27 de julho de 1988, o então Deputado Ulysses Guimarães encerrou os trabalhos da Assembleia Nacional Constituinte, da qual era presidente e apresentou a nova Carta Magna do país: "Essa será a Constituição cidadã, porque recuperará como cidadãos milhões de brasileiros, vítimas da pior das discriminações: a miséria [...] O povo nos mandou aqui para fazê-la, não para ter medo. Viva a Constituição de 1988! Viva a vida que ela vai defender e semear!”

Em 05 de outubro de 1988 houve a promulgação da Constituição. Foi um momento marcado pela euforia e pelo entusiasmo gerado, sobretudo, pelos ideais contidos na nova carta constitucional. Após décadas de autoritarismo e despotismo, o Brasil respira o sonho da liberdade. Vejamos outro trecho do discurso efervescente do deputado Ulysses Guimarães, quando na apresentação da Constituição Federal de 1988: “Declaro promulgada. O documento 
da liberdade, da dignidade, da democracia, da justiça social do Brasil. Que Deus nos ajude; que isso se cumpra." (GUIMARÃES, 1988)

A começar pelos princípios fundamentais, a Constituição Federal de 1988 tem por base valores éticos que buscam ressaltar o aspecto a dignidade humana. Conforme o Art. $1^{\circ}$ :

Art. $1^{\circ}$ A República Federativa do Brasil, formada pela união indissolúvel dos Estados e Municípios e do Distrito Federal, constitui-se em Estado Democrático de Direito e tem como fundamentos: I - a soberania; II - a cidadania; III - a dignidade da pessoa humana; IV - os valores sociais do trabalho e da livre iniciativa; V - o pluralismo político. Parágrafo único. Todo o poder emana do povo, que o exerce por meio de representantes eleitos ou diretamente, nos termos desta Constituição. (BRASIL, 2007, p. 13)

A Constituição Federal de 1988 dispõe do mais avançado aparato jurídico já consolidado numa lei na história do nosso país. É a nossa 'Lei Maior', 'Lei Suprema', a partir da qual derivam os direitos e deveres do cidadão, as obrigações do Estado e as demais normativas que organizam a vida social. Muito se avançou com a (re) conhecida 'Constituição Cidadã'.

\section{Outros conceitos em Gestão Pública: Governança; Eficiência, Eficácia e Efetividade; Governo Eletrônico; Transparência; Accountability.}

O conceito de governança se refere à capacidade que um governo tem para a execução de seus planos e metas, por meio de decisões e execuções. Gonçalves (2005) trabalha a ideia de que governança está relacionada à garantia de uma administração que alcance os resultados planejados, com eficiência, sem necessariamente o uso da coerção. Em outras palavras, diz respeito aos meios e processos que são utilizados pelo gestor para produzir resultados eficazes.

Eficiência, Eficácia e Efetividade constituem palavras de ordem quando se trata de uma gestão de qualidade.

A Eficiência está relacionada com a ideia de fazer acoisa certa, sem desperdício de recursos, nem perda de tempo. O princípio da eficiência foi adaptado para a gestão pública com o objetivo de reduzir o tempo nos atendimentos, dar maior celeridade aos atos públicos e acabar com os excessos de burocracia, que em muito emperram a máquina pública. Este princípio 
inclui ainda a busca pela superação de modelos e padrões ultrapassados, que já não atendem mais às demandas postas. A qualificação da força de trabalho, a racionalização das metodologias de trabalho, a otimização e modulação de recursos humanos, materiais e financeiros constituem estratégias para garantir a eficiência das ações prestadas por agentes públicos.

A Eficácia resulta da relação entre os objetivos previstos/planejados e os resultados alcançados, de fato. A análise da eficácia dos serviços públicos só é possível por meio da avaliação dos mesmos. A partir da avaliação, se pode definir - quantitativa e qualitativamente - o quanto foi alcançado daquilo que foi planejado.

A Efetividade está relacionada ao atendimento de expectativas do público. Cabem os seguintes questionamentos para se descobrir a efetividade: o atendimento foi satisfatório? Resolveu o meu problema? A efetividade, pois, busca a garantia, a efetivação, a satisfação da demanda.

Os três conceitos (eficiência, eficácia e efetividade) compõe um conjunto amplo de indicadores que balizam a execução do serviço público. Devem fazer parte de todas as instituições e o seu uso deve ser constante, pois, conforme afirmou Aristóteles, "somos o que repetidamente fazemos. A excelência, portanto, não é um feito, mas um hábito" (ARISTÓTELES, apud HERRERA, 2006)

O conceito de transparência está coadunado no que já foi estudado sobre o princípio da publicidade. Na gestão pública, os atos administrativos devem ser claramente divulgados para que a população possa ter controle sobre a eficiência, a eficácia e a efetividade dos mesmos.

Por fim, o conceito de accountability está relacionado à responsabilização, fiscalização e avaliação da prestação de serviços públicos. O termo é oriundo da língua inglesa e a sua tradução aproximada para a língua portuguesa seria prestação de contas.

\section{A Lei de Responsabilidade Fiscal e seu impacto na Gestão Pública}

Como dito, em decorrência dos problemas enfrentados pela Gestão Pública, há uma forte necessidade de se aprofundar os estudos e conhecimentos que envolvem tal instituto. 
Sendo portanto, de vital importância que os gestores públicos estejam preparados e qualificados para enfrentar os problemas e os desafios enfrentados.

Partindo deste pressuposto, buscamos durante o presente trabalho verificar, através de uma revisão de literatura, quais os principais problemas e desafios enfrentados pelos gestores públicos.

Com o intuito de verificar estes problemas, realizou-se uma revisão bibliográfica sobre o tema em questão. Onde foi realizado uma busca na internet e foram encontrados apenas artigos abordando o assunto.

Na obra Responsabilidade na gestão pública: os desafios dos municípios, 2008, elaborada pela Câmara de Deputados foram analisados dados de eficiência nos municípios brasileiros após a implantação da Lei de Responsabilidade Fiscal (Lei Complementar $\mathrm{n}^{\circ}$ 101/2000). De acordo com a referida obra:

\begin{abstract}
Os dados municipais da despesa com pessoal mostram que, dos 5.212 municípios observados, a média de despesa de pessoal dividida pela receita corrente líquida encontra-se em $42,6 \%$ no primeiro período (1998 a 2000) e em 42,0\% no segundo período (2001 a 2004). Portanto, apesar de inflexível, o limite imposto pela lei está distante da realidade dos gastos municipais, e há indícios de que esse limite tomou como base a realidade fiscal dos estados brasileiros à época de formulação da lei (Linhares, José. 2008. p. 64)
\end{abstract}

Portanto, a Lei de Responsabilidade Fiscal veio para impor limites para os gatos entre municípios e estados. Tendo imposto um limite de $60 \%$ da receita corrente liquida para gastos com pessoal e encargos.

Jose Linhares destaca que:

\begin{abstract}
A LRF fixou em $60 \%$ da receita corrente o teto para gasto com pessoal de cada estado com todos os Poderes. O sublimite para o Executivo é de $54 \%$, e é este que será aqui comentado. Como no último mandato o aumento da receita superou o da folha salarial, foi possível reduzir tal índice: recuou para 40,8\% da receita em 2006. Exemplificando, entre dezembro de 2002 e dezembro de 2006, essa razão diminuiu em SP (de 48,0\% para $42,8 \%$ da receita), $\mathrm{RS}(48,8 \%$ para $41,3 \%)$, MA $(40,7 \%$ para $35,6 \%)$ e RJ $(37,5 \%$ para 27,5\%). (Linhares, José. 2008. p. 64)
\end{abstract}

Ainda de acordo com José Linhares:

Os municípios que tinham gastos excessivos reduziram seus gastos e os que apresentavam uma porcentagem muito baixa de gastos com pessoal como proporção 
da receita corrente líquida passaram a gastar mais. A média de gastos entre um período e outro permanece praticamente a mesma. No entanto, o desvio padrão passou de 0,22 para 0,07 (Linhares, José. 2008. p. 67).

Com relação as dívidas consolidadas, José Linhares (2008), dispôs que:

\begin{abstract}
Nota-se que a parcela de municípios com dívida negativa (ou seja, credores) ou com uma relação de dívida de até 0,2 era consideravelmente alta $(67,03 \%)$. Portanto, os limites de endividamento da LRF, na ocasião em que foram fixados, estavam fora dos padrões da grande maioria dos municípios brasileiros (Linhares, José. 2008. p. 68).
\end{abstract}

Portanto, nota-se que a Lei de Responsabilidade Fiscal apesar dos inúmeros esforços não foi suficiente a fim de sanar os problemas enfrentados pela gestão pública, haja vista que seu impacto pode não ser tão bom para todos os municípios uma vez que aqueles que possuíam gastos abaixo do teto de $60 \%$ poderiam acabar tendo tal medida como incentivo para os gastos com pessoal, gerando maior efeito apenas naqueles que apresentavam-se acima da média.

\title{
Considerações Finais
}

Vimos que a política pública se constitui numa das principais ferramentas de intervenção na questão social. Sua importância está na capacidade de transformação da realidade, na medida em que pode alcançar os excluídos da cidadania oficial. Para isso, nós profissionais da área social devemos assumir o compromisso de lutar pela justiça social e pela melhoria das condições de vida das classes subalternas. Isso só é possível por meio do exercício do controle social e da participação.

Sabendo que as políticas públicas são ações coletivas que visam à orientação e garantia de direitos perante a sociedade, no qual envolve compromissos e tomadas de decisões que almejam determinadas finalidades, essas ações governamentais devem ser sempre planejadas com objetivos, metas, efeitos e com efetividade. E o papel da sociedade é muito importante perante essas ações governamentais.

Portanto, imprescindível se faz discutir e analisar melhor as políticas públicas de forma a buscar o combate aos problemas enfrentados pelos Gestores Públicos. Entretanto, para que este objetivo seja alcançado torna-se importante que os representantes da sociedade tenham 
conhecimento de seus direitos, dos espaços de participação em que podem atuar e, de que maneira seria possível atuar nestes espaços, e quais as outras formas de pressão para monitorar impactos sociais negativos através das políticas públicas.

Sua abrangência tange pontos estratégicos do nosso fazer profissional, a exemplo do diagnóstico, planejamento, execução, monitoramento e avaliação. A eficiência, eficácia e efetividade também são balizas.

O conceito de Gestão Pública significa tentativas. Para encerrarmos este trabalho, deixamos a mensagem a seguir: "A alegria está na luta, na tentativa, no sofrimento envolvido. Não na vitória propriamente dita." (Mahatma Gandhi).

\section{Referências}

BARACCHINI, Sabrina Addison. A Inovação presente na Administração Pública Brasileira. RAE - Revista de Administração de Empresas. Abr./Jun. 2002 São Paulo, v. 42. n. 2. p. 104109.

BRASIL. Constituição (1988). Constituição da República Federativa do Brasil. 35. ed. São Paulo: Saraiva, 2005.

DEMO, Pedro. Pobreza Política. $5^{\text {a }}$ edição - Campinas, SP: Autores associados, 1996. (Coleção polêmicas do nosso tempo; v. 27)

FERREIRA, Michelle Karen de Brunis. As novas configurações da Gestão Pública: comunicação, conhecimento e pessoas. Disponível em:http://www.egem.org.br/artigos/index.php?cod_artigo=9. Acesso em 15/01/2019.

GAMA, Cláudio Márcio Araújo da. Política: o verdadeiro significado da participação. Disponível em: http://www.administradores.com.br/informe-se/artigos/politica-o-verdadeirosignificado-da-participacao/20242/. Acesso em 14.01.19

GUIMARÃES, Ulisses. Promulgação da Constituição de 1988. YouTube, 10 de junho de 2008. Disponível em http://www.youtube.com/watch?v=mlSDpvriBeM. Acesso em 16 jan. 2019.

HERRERA, Wagner. Eficiência, Eficácia e Efetividade. Disponível em: http://www.artigos.com/artigos/sociais/administracao/eficiencia,-eficacia-e-efetividade918/artigo/. Acesso em 16/01/2019. 
LINDEMBERG, Antonio Henrique. Princípios Constitucionais da Administração Pública. S.D. Disponível no site: http://www.buscalegis.ufsc.br/revistas/files/journals/2/articles/32832/public/32832-40730-1PB.pdf. Acesso em 14/01/2019.

LINHARES, José. Responsabilidade na gestão pública: os desafios dos municípios. Brasília: Câmara dos Deputados, Edições Câmara, 2008.

MARTINS, Cristiane Fortes Nunes. O Princípio da Eficiência na Administração Pública. [2008]. Retirado do endereço eletrônico: www.faete.edu.br/revista/artigo1.doc. acesso em $12 / 01 / 2019$.

MENEZES, Samira Birck de. Os princípios da administração pública aplicados ao direito registral e notarial. Revista Eletrônica do Curso de Direito Da UFSM. Setembro de 2008 Vol. 3 N.3, p. 01-13.

PEREIRA, Isabel Brasil. Dicionário da educação profissional em saúde / Isabel Brasil Pereira e Júlio César França Lima. . 2.ed. rev. ampl. - Rio de Janeiro: EPSJV, 2008.

SOUZA, Herbert. Participação. $\quad$ Disponível em: http://www.tecsi.fea.usp.br/eventos/Contecsi2004/BrasilEmFoco/port/polsoc/partic/apresent/a present.htm. Acesso em 17.01.19.

\section{Como citar este artigo (Formato ABNT):}

NUNES, Istefani De Sá; CAFFÉ FILHO, Hesler Piedade. Perspectivas e Desafios da Gestão Pública Contemporânea. Id on Line Rev.Mult. Psic., 2019, vol.13, n.45, p. 715-733. ISSN: 1981-1179.

Recebido: 05/05/2019

Aceito 07/05/2019 